\title{
Canine heartworm disease (Dirofilaria immitis) in Western Europe: survey of veterinary awareness and perceptions
}

\author{
Claudio Genchi ${ }^{1 *}$, Dwight Bowman ${ }^{2}$ and Jason Drake ${ }^{3}$
}

\begin{abstract}
Background: This survey examines the experience and opinion of veterinarians with canine heartworm (HW; Dirofilaria immitis) infection in non-endemic and endemic areas of Europe.

Methods: A questionnaire was distributed by e-mail to veterinary practitioners within non-endemic countries including UK, Germany, and Netherlands, non-endemic regions of France, Spain, Italy and endemic regions of France, Spain and Italy. The main questions were about the HW cases seen in the last 12 months, if the number of cases had changed over the last 5 years and practitioner awareness of the ESCAAP Guidelines on HW. Additional questions examined practitioner perception regarding the risk of HW for pets travelling in endemic areas and the use of preventatives including veterinary perception of pet owner compliance.

Results: Overall 584 responses, 389 from non-endemic countries and regions and 195 from endemic regions were obtained. Most of the cases were seen in endemic regions, although in Germany 20\% of veterinarians reported cases of HW infection. Overall, 10\% of practitioners in non-endemic areasand 12\% in endemic areas, respectively, reported an increasing number of cases. The practitioner awareness of ESCCAP guidelines is low. Veterinarians responded that preventative drugs were prescribed to most client dogs in endemic areas and most practitioners rated owner compliance as good or excellent in following the veterinarian's guidance for HW prevention. Overall $63 \%$ of veterinarians responded that owners are more or less aware of the HW risk traveling with their dogs in endemic areas. Forty four percent of responders in non-endemic regions considered it somewhat likely to very likely that HW infection will become endemic in their regions.
\end{abstract}

Conclusions: In both non-endemic and endemic countries at least 1 responding practitioner admitted seeing a case of canine HW infection and has shown awareness regarding infection. Ten percent of practitioners stated that the number of cases is increasing. Although the number of owners traveling with their dogs was low, the perception of surveyed veterinarians was that owners were quite aware of the HW risk for their dogs. Several veterinary practitioners believe that HW infection could become endemic in their non-endemic area within the next 10 years.

Keywords: Heartworm, Dirofilaria immitis, Dog, Veterinary awareness, Europe

\footnotetext{
* Correspondence: claudio.genchi@unimi.it

1 Department of Veterinary Science and Animal Health, Università degli Studi di Milano, via Celoria 10, 20133 Milano, Italy

Full list of author information is available at the end of the article
} 


\section{Background}

Historically, canine heartworm (HW, Dirofilaria immitis) infection in Europe was localized in the southern areas and until the middle of the 1980's the most endemic area was northern Italy [1], where the parasite was first observed by Birago in 1626 [2] in a greyhound dog at autopsy. However, there has been significant debate over the last few years regarding the risk of spread of dirofilarial parasites to non-endemic European areas as a consequence of changing climate, dog movement and relocation [3-5]. Currently, HW infection has been reported from non-endemic areas of both central and southern Italy [6-8] and in some northern and north-eastern European countries such as Czech Republic, Hungary, Serbia, Slovak Republic, Switzerland [4,9], and recently in Romania [10] and Poland [11]. Furthermore, D. immitis larvae have been found in mosquitoes in Germany [12].

People frequently travel with their pets between nonendemic and endemic areas. If travelling dogs become HW infected, they can act as donors of microfilariae to local mosquito species making spread of the infection to naïve canine population possible. Heartworm infection in dogs is a chronic condition and most infected dogs do not show any symptoms for months or years, depending on the worm burden [13].

This survey was conducted to examine the opinions and experiences of veterinarians with canine HW infection in both non-endemic and endemic areas as well as their awareness of European Scientific Counsel Companion Animal Parasites Guidelines on prevention of HW in Europe [14]. This is the first survey that has tried to assess the condition throughout Europe, not just in individual countries. The survey was not all inclusive, but it is a major start in obtaining information from practitioners as to where they believe heartworm is located.

\section{Methods}

An online survey was developed and provided to companion animal veterinarians from June through September 2013 across D. immitis non-endemic countries including United Kingdom, Germany and Netherlands, nonendemic regions of France, Spain, Italy and endemic regions of France, Spain and Italy. Over 5382 questionnaires, with a minimum of 300 questionnaires per country, were email distributed to veterinary clinics with the goal of obtaining at least 100 responses per country. The clinics were targeted through a combination of purchased veterinary email lists as well as email addresses that Novartis had accumulated independently from veterinarians with the goal of communicating to as many veterinarians as possible. In addition, 1010 flyers with links to the online survey were printed and delivered to veterinary clinics in Italy, Spain and France to encourage participation. Two sets of questionnaires were used for non-endemic
Table 1 Number of cases of canine heartworm (Dirofilaria immitis) infections: non-endemic regions seen by the practitioners in the last 12 months

\begin{tabular}{ccccccc}
\hline & \multicolumn{5}{c}{$\begin{array}{c}\text { Number of cases: non-endemic } \\
\text { countries/regions }\end{array}$} & \\
\cline { 2 - 5 } Country & $\mathbf{0}$ & $\mathbf{1}$ & $\mathbf{2 - 5}$ & $\mathbf{6 - 9}$ & $\mathbf{> 1 0}$ & Responders \\
\hline UK & 30 & 1 & 2 & 0 & 0 & 33 \\
Germany & 40 & 38 & 20 & 3 & 0 & 101 \\
Netherlands & 32 & 1 & 1 & 0 & 0 & 34 \\
France & 80 & 4 & 1 & 0 & 1 & 86 \\
Spain & 57 & 7 & 1 & 1 & 2 & 68 \\
Italy & 51 & 10 & 5 & 0 & 1 & 67 \\
Total (\%) & $290(74)$ & $61(16)$ & $30(8)$ & $4(1)$ & $4(1)$ & 389 \\
\hline
\end{tabular}

or endemic regions. The questionnaires were available in English, German, Dutch, French, Spanish and Italian. Depending on response rates, a reminder was sent out 2 weeks after the first email. The main questions for practitioners working in both non-endemic and endemic areas were:

- Over the last 12 months, how many cases of HW infection have you seen at your clinic?

- How have the number of HW cases changed over the last 5 years?

- How aware are you of the ESCCAP guidelines on HW infection?

Further questions were posed to veterinarians working in endemic areas about the use of HW preventative drugs and the compliance of animal owners in following guidance regarding HW prevention. In non-endemic regions, additional questions were about the percentage of dog owners travelling with their pets in endemic regions, the perception of veterinarians and owners of the risk of HW infection being brought into non-endemic regions by dogs travelling in endemic areas, and how likely did the veterinarians think it might be that HW will become endemic within the next 10 years in their region/country.

Table 2 Number of cases of canine heartworm (Dirofilaria immitis) infections: endemic regions seen by the practitioners in the last $\mathbf{1 2}$ months

\begin{tabular}{ccccccc}
\hline & \multicolumn{4}{c}{ Number of cases: endemic regions } & \\
\cline { 2 - 5 } Country & $\mathbf{5}$ & $\mathbf{1 - 5}$ & $\mathbf{6 - 1 0}$ & $\mathbf{1 1 - 2 5}$ & $\mathbf{> 2 6}$ & Responders \\
\cline { 2 - 6 } France & 32 & 10 & 1 & 2 & 2 & 47 \\
Spain & 6 & 21 & 9 & 3 & 2 & 41 \\
Italy & 45 & 58 & 2 & 1 & 1 & 107 \\
Total (\%) & $83(42)$ & $89(46)$ & $12(6)$ & $6(3)$ & $5(3)$ & 195 \\
\hline
\end{tabular}


Table 3 Change in number of cases of canine heartworm (Dirofilaria immitis) infections over the last $\mathbf{5}$ years

\begin{tabular}{|c|c|c|c|c|c|}
\hline \multirow[b]{2}{*}{ Country } & \multicolumn{4}{|c|}{ Clinics reporting changes in number of cases } & \multirow[b]{2}{*}{ Total responders $(\%)$} \\
\hline & Increase in cases (\%) & Decrease in cases (\%) & No change in cases (\%) & No cases $(\%)$ & \\
\hline UK (non-endemic) & $2(5)$ & $0(0)$ & $1(1)$ & $30(11)$ & $33(9)$ \\
\hline Germany (non-endemic) & $20(51)$ & $3(50)$ & $38(48)$ & $40(15)$ & $101(26)$ \\
\hline Netherlands (non-endemic) & $1(3)$ & $0(0)$ & $1(1)$ & $32(12)$ & $34(9)$ \\
\hline France (non-endemic) & $1(3)$ & $2(33)$ & $7(9)$ & $76(29)$ & $86(22)$ \\
\hline France (endemic) & $5(22)$ & $4(7)$ & $9(18)$ & $29(43)$ & $47(24)$ \\
\hline Spain (non-endemic) & $2(5)$ & $1(17)$ & $18(23)$ & $47(18)$ & $68(17)$ \\
\hline Spain (endemic) & $11(48)$ & $11(20)$ & $14(29)$ & $5(8)$ & $41(21)$ \\
\hline Italy (non-endemic) & $13(33)$ & $0(0)$ & $14(18)$ & $40(15)$ & $67(17)$ \\
\hline Italy (endemic) & $7(30)$ & $41(73)$ & $26(53)$ & $33(49)$ & $107(55)$ \\
\hline Total non-endemic & 39 & 6 & 79 & 265 & 389 \\
\hline Total endemic & 23 & 56 & 49 & 67 & 195 \\
\hline
\end{tabular}

\section{Results}

A total of 584 responses, representing a response rate of approximately 9.1\%, were obtained including 389 from non-endemic areas (UK: 33, Germany: 101, Netherlands: 34; non-endemic areas of France: 86, Spain: 68, Italy: 67) and 195 from endemic areas (France: 47, Spain: 41, and Italy: 107).

Twenty-five percent of responders in non-endemic regions had seen one or more cases over the last 12 months. Ten percent reported seeing 2-9 cases over the past 12 months. More than 10 cases were not reported by responders from any of the non-endemic countries (UK, Germany and Netherlands). Twenty three percent of veterinary practitioners in Germany (23/101) reported
2-9 cases, $4(2 \%, 4 / 221)$ reported more than 10 cases in non-endemic areas of France, Italy and Spain (Table 1). In endemic regions, 32\% (15/47), 85\% (35/41) and 58\% (62/107) of veterinary practitioners from France, Spain and Italy, respectively, reported cases of HW infection in the last 12 months. Two veterinary practitioners in France and in Spain, and one in Italy, equivalent to $2.6 \%$ of responders from endemic areas, reported more than 26 cases. Eleven to 25 cases were seen by 2 veterinary practitioners in France, 3 in Spain and 1 in Italy (Table 2).

Overall, 34\% (62/584) of practitioners reported an increasing number of $\mathrm{HW}$ cases. In non-endemic countries, $14 \%(23 / 168)$ reported an increase, $2 \%(3)$ a decrease and 24\% (40) no change (Table 3); although in

Table 4 How aware are the veterinary practitioners of the ESCCAP Heartworm (Dirofilaria immitis) Guidelines

\begin{tabular}{|c|c|c|c|c|c|c|}
\hline \multirow[b]{3}{*}{ Country } & \multicolumn{5}{|c|}{ Awareness of ESCCAP Heartworm Guidelines } & \multirow[b]{3}{*}{ Responders } \\
\hline & \multicolumn{5}{|c|}{ Number clinics responding (\% responding) } & \\
\hline & Not aware & Slightly aware & Moderately aware & Quite aware & Very aware & \\
\hline UK (non-endemic) & $22(67)$ & $5(15)$ & $3(9)$ & $3(9)$ & $0(0)$ & 33 \\
\hline Germany (non-endemic) & $40(40)$ & $38(38)$ & $20(20)$ & $3(3)$ & $0(0)$ & 101 \\
\hline Netherlands (non-endemic) & $32(94)$ & $1(3)$ & $1(3)$ & $0(0)$ & $0(0)$ & 34 \\
\hline France (non-endemic) & $63(73)$ & $9(10)$ & $10(12)$ & $2(2)$ & $2(2)$ & 86 \\
\hline France (endemic) & $29(62)$ & $9(19)$ & $4(9)$ & $4(9)$ & $1(2)$ & 47 \\
\hline Spain (non-endemic) & $25(37)$ & $13(19)$ & $22(32)$ & $6(9)$ & $2(3)$ & 68 \\
\hline Spain (endemic) & $15(37)$ & $4(10)$ & $10(24)$ & $9(22)$ & $3(7)$ & 41 \\
\hline Italy (non-endemic) & $35(52)$ & $11(16)$ & $14(21)$ & $5(7)$ & $2(3)$ & 67 \\
\hline Italy (endemic) & $56(52)$ & $19(18)$ & $20(19)$ & $8(7)$ & $4(4)$ & 107 \\
\hline Total (non-endemic) & $217(56)$ & $77(20)$ & $70(18)$ & $19(5)$ & $6(2)$ & 389 \\
\hline Total (endemic) & $100(51)$ & $32(16)$ & $34(17)$ & $21(11)$ & $8(4)$ & 195 \\
\hline Total & $317(54)$ & 109 (19) & $104(18)$ & $40(7)$ & $14(2)$ & 584 \\
\hline
\end{tabular}


Table 5 Over the last 12 months, approximately what percentage of dogs in your clinic within an endemic area, have been prescribed preventative treatment against heartworm (Dirofilaria immitis)?

\begin{tabular}{lccccccc}
\hline & \multicolumn{5}{c}{ Percentage of dogs prescribed heartworm preventative within a clinic in an endemic area } \\
\cline { 2 - 6 } Country & None & $\leq \mathbf{2 5 \%}$ & $\mathbf{2 6 - 5 0 \%}$ & $\mathbf{5 1 - 7 5 \%}$ & $\mathbf{7 6 - 9 9 \%}$ & All & Responders \\
\cline { 2 - 7 } & $24(51)$ & $9(19)$ & $2(4)$ & $9(19)$ & $2(4)$ & $1(2)$ & 47 \\
France & $0(0)$ & $8(20)$ & $6(15)$ & $5(12)$ & $13(32)$ & $9(22)$ & 41 \\
Spain & $0(0)$ & $3(3)$ & $2(2)$ & $6(6)$ & $35(33)$ & $61(57)$ & 107 \\
Italy & $24(12)$ & $20(10)$ & $10(5)$ & $20(10)$ & $50(26)$ & $71(36)$ & 195 \\
Total & & & & &
\end{tabular}

Germany, 20\% of veterinarians (20/101) reported an increasing number of cases. Overall, in non-endemic regions of France, Spain and Italy, 7\% (16/221) of veterinarians reported an increase of HW cases, 1.3\% (3) a decrease and 18\% (39) no change (Table 3). The highest increase of cases was reported from non-endemic Italy $(13 / 67,19 \%)$. In endemic regions of France, Spain and Italy, overall 9\% of responders (18/195) reported an increase of $\mathrm{HW}$ cases, 29\% (56) a decrease and 25\% (49) no change. The highest number of increasing cases was reported from Spain (11/41, 27\%; Table 3).

Most veterinary practitioners from both non-endemic and endemic areas were not aware of ESCCAP HW guidelines $(317 / 584,54 \%)$ and only $9 \%$ were quite or very aware of the guidelines (54/389, 9\%) (Table 4). However, $54 \%$ of veterinarians from endemic regions of Spain (22/41) and 30\% from endemic regions of Italy $(30 / 107)$ reported to be moderately-very aware about the guidelines and $41 \%(17 / 41)$ and 30\% (32/107), respectively, declared that guidelines are well implemented into their clinical practice.

Overall, $12 \%$ of veterinarians in endemic regions did not prescribe a preventative treatment against HW infection over the last 12 months. It was prescribed by $36 \%$ of responders to all the dogs in their practice while from $5 \%$ to $25 \%$ of responders prescribed preventatives to different percentages of dogs (from less than $25 \%$ to $99 \%$ ) (Table 5 ). One hundred and forty (74\%) veterinarians rated owner compliance in following the guidance for HW prevention to be excellent or good, $19 \%$ reasonable and $9 \%$ poor or non-compliant (Table 6).

The percentage of dog owners that had traveled from non-endemic to endemic countries/regions estimated by the veterinary practitioners is shown in Table 7 . The percentages between $0-10 \%$ and $11 \%-25 \%$ account for the higher frequencies ( $40 \%$ and $34 \%$, respectively), while percentages between $51 \%-75 \%$ and $76 \%-100 \%$ account for $6 \%$ and $1 \%$ only, respectively (Table 7 ). In non-endemic regions, Fifty three percent of veterinary practitioners (207/389) consider that there is no or little risk of introduction of $\mathrm{HW}$ infection through traveling dogs, 41\% (163/389) declare some or moderate risk and $5 \%$ high risk (19/389; Table 8$)$. Thirty seven percent $(142 / 389)$ of practitioners think that owners are not aware of the risk of HW when they travel with their dogs in endemic areas, 39\% (153) think the owners are slightly aware, $23 \%$ (89) think the owners are somewhat or moderately aware and only $1 \%(5)$ think that owners are very aware (Table 9).

Table 10 shows the perception of veterinarians in nonendemic countries/areas that HW should become endemic in their regions in the next 10 years. Twenty three percent think that this is not likely, 33\% that it is slightly, $38 \%$ that it is somewhat or moderately likely and $6 \%$ that it is very likely.

Table 6 How do you rate the compliance of companion animal owners that live in your endemic area in following guidance regarding heartworm (Dirofilaria immitis) prevention in their dogs?

\begin{tabular}{lcccccc}
\hline & \multicolumn{5}{c}{ Veterinary rating of pet owner compliance in endemic regions } \\
\cline { 2 - 5 } & \multicolumn{5}{c}{ Number clinics responding (\% responding) } & Non-compliant \\
\cline { 2 - 5 } & Excellent & Good & Reasonable & Poor & $7(15)$ & Responders \\
\hline France & $10(21)$ & $7(15)$ & $19(40)$ & $4(9)$ & $3(0)$ & 47 \\
Spain & $0(0)$ & $21(51)$ & $17(41)$ & $3(3)$ & $0(0)$ & 41 \\
Italy & $26(24)$ & $76(71)$ & $2(2)$ & $10(5)$ & $7(4)$ & 107 \\
Total & $36(18)$ & $104(53)$ & $38(19)$ & & 195 \\
\hline
\end{tabular}


Table 7 What percentage of companion animal owners from your non-endemic country/region do you think travel with their pets to heartworm (Dirofilaria immitis) endemic areas such as Spain, south of France, Italy, Greece, Turkey and other countries along the Adriatic coast?

\begin{tabular}{|c|c|c|c|c|c|c|}
\hline \multirow[b]{3}{*}{ Country } & \multicolumn{5}{|c|}{ Percentage of pet owners that travel with pets from non-endemic regions to endemic regions } & \multirow[b]{3}{*}{ Responders } \\
\hline & \multicolumn{5}{|c|}{ Number clinics responding (\% responding) } & \\
\hline & $0-10 \%$ & $11-25 \%$ & $26-50 \%$ & $51-75 \%$ & $76-100 \%$ & \\
\hline UK & $21(64)$ & $8(24)$ & $4(12)$ & $0(0)$ & $0(0)$ & 33 \\
\hline Germany & $29(29)$ & $39(39)$ & $26(26)$ & $6(6)$ & $1(1)$ & 101 \\
\hline Netherlands & $15(44)$ & $13(38)$ & $2(6)$ & $4(12)$ & $0(0)$ & 34 \\
\hline France & $38(44)$ & $34(40)$ & $10(12)$ & $4(5)$ & $0(0)$ & 86 \\
\hline Spain & $26(38)$ & $21(31)$ & $17(25)$ & $4(6)$ & $0(0)$ & 68 \\
\hline Italy & $25(37)$ & $19(28)$ & $15(22)$ & $6(9)$ & $2(3)$ & 67 \\
\hline Total & $154(40)$ & $134(34)$ & 74 (19) & $24(6)$ & $3(1)$ & 389 \\
\hline
\end{tabular}

\section{Discussion}

As is true for many surveys, participation was entirely voluntary which may lead to some bias in responses. Individuals with an interest in the topic are more likely to participate. Although the goal of 100 responders was not achieved in all the countries included in the survey, the overall number of responders is sufficient to draw some conclusions.

In all countries, at least one veterinary practitioner has seen at least one case of canine HW infection in the last 12 months. Nevertheless, while the number of responders from non-endemic countries such as UK and Netherland is low (33 and 34, respectively), probably because the cases are quite rare and diagnosed in imported or relocated dogs $[15,16]$, the number of responders from Germany was quite significant, confirming the empirical data that $\mathrm{HW}$ infection is quite frequently diagnosed in travelling or relocated dogs [4]. Furthermore, the spreading of autochthonous cases of $D$. repens, the agent of subcutaneous dirofilariosis [16], has alerted German practitioners to Dirofilaria infections. As expected, fewer veterinarians from non-endemic regions reported cases than veterinarians from endemic regions, although the number of veterinarians reporting cases in Germany (61 cases) is the highest for non-endemic areas including France, Spain and Italy where the infection is endemic in many areas. Furthermore, the percent of practitioners that declared an increasing number of cases is higher in non-endemic areas than in endemic ones, confirming the spread of infection. Most cases were seen in the last 5 years in Germany, in non-endemic areas of Italy and in endemic areas of Spain possibly as a consequence of changing climate, confirming the provisional expansion of the risk to naïve areas $[17,18]$. In endemic regions, probably more than 357 cases (89 responder at 1-5 cases, 12 at 6-10 cases, 6 at 11-25 cases, and 5 at 26 or more cases) of heartworm in the last 12 months were reported by veterinary practitioners in France, Spain and Italy, confirming that in spite of the use

Table 8 What is your perceived risk of heartworm (Dirofilaria immitis) infection being brought back into your non-endemic country/region by traveling dogs

\begin{tabular}{|c|c|c|c|c|c|c|c|}
\hline \multirow[b]{3}{*}{ Country } & \multicolumn{5}{|c|}{$\begin{array}{l}\text { Perceived risk of heartworm when traveling with pets return to non-endemic areas from endemic } \\
\text { areas }\end{array}$} & \multirow[b]{3}{*}{ Total risk } & \multirow[b]{3}{*}{ Responders } \\
\hline & \multicolumn{5}{|c|}{ Number clinics responding (\% responding) } & & \\
\hline & No risk & Little risk & Some risk & Moderate risk & High risk & & \\
\hline UK & $2(6)$ & $17(52)$ & $13(36)$ & $1(3)$ & $0(0)$ & $31(94)$ & 33 \\
\hline Germany & $8(8)$ & $29(29)$ & $34(34)$ & $22(22)$ & $8(8)$ & $93(92)$ & 101 \\
\hline Netherlands & $3(9)$ & $12(35)$ & $15(44)$ & $4(12)$ & $0(0)$ & $31(91)$ & 34 \\
\hline France & $13(15)$ & $59(69)$ & $11(13)$ & $2(2)$ & $1(1)$ & $73(85)$ & 86 \\
\hline Spain & $12(18)$ & $30(44)$ & $17(25)$ & $6(9)$ & $3(4)$ & $56(82)$ & 68 \\
\hline Italy & $6(9)$ & $16(24)$ & 25 (37) & $13(19)$ & $7(10)$ & $61(91)$ & 67 \\
\hline Total & $44(11)$ & $163(42)$ & $115(30)$ & $48(12)$ & $19(5)$ & 345 (89) & 389 \\
\hline
\end{tabular}


Table 9 How do you think companion animal owners are aware of the risk of heartworm (Dirofilaria immitis) when traveling to heartworm endemic areas?

\begin{tabular}{|c|c|c|c|c|c|c|}
\hline \multirow[b]{3}{*}{ Country } & \multicolumn{5}{|c|}{ Perceived pet owner awareness of heartworm risk when traveling from non-endemic areas to endemic areas } & \multirow[b]{3}{*}{ Responders } \\
\hline & \multicolumn{5}{|c|}{ Number clinics responding (\% responding) } & \\
\hline & Not aware & Slightly aware & Somewhat aware & Moderately aware & Very aware & \\
\hline UK & $16(48)$ & $14(42)$ & $2(6)$ & $1(3)$ & $0(0)$ & 33 \\
\hline Germany & $35(35)$ & $49(49)$ & $13(13)$ & $3(3)$ & $1(1)$ & 101 \\
\hline Netherlands & $8(24)$ & $16(47)$ & $4(12)$ & $5(15)$ & $1(3)$ & 34 \\
\hline France & $46(53)$ & $29(34)$ & $10(12)$ & $1(1)$ & $0(0)$ & 86 \\
\hline Spain & $21(31)$ & $21(31)$ & $17(25)$ & $6(9)$ & $3(4)$ & 68 \\
\hline Italy & $16(24)$ & $24(36)$ & $18(27)$ & $9(13)$ & $0(0)$ & 67 \\
\hline Total & $142(37)$ & 153 (39) & $64(16)$ & $25(6)$ & $5(1)$ & 389 \\
\hline
\end{tabular}

of preventative drugs, the infection is still frequent. Of note is that the number of practitioners prescribing preventative drugs to all their clients' dogs is quite low in the endemic areas of France and Spain. Only in Italy are more than half of the responding veterinarians prescribing preventative drugs to all their clients' dogs and this may be a potential reason for the consistent decrease in cases seen in the country.

Overall, the awareness of ESCCAP HW guidelines is low, although veterinary practitioners in endemic regions are, on average, over twice as aware compared with colleagues in non-endemic regions, but quite a few claim to have implemented the guidelines into their clinical practice. Nevertheless, the perception of owner compliance in following the practitioners' guidance regarding HW prevention in their dogs is good or excellent in most endemic countries.

Regarding the movement of dogs, only limited pet travel was noted amongst respondents. More than 60\% of respondents stated that less than $25 \%$ of pets attending their clinics would likely travel to an endemic HW region. For instance, from the UK, most veterinary practitioners have stated that no pets would travel to endemic areas. On the other hand, 50\% of practitioners from non-endemic Italy and Germany declare there is some risk to a high risk that HW could be introduced by dogs traveling in endemic areas, and more than $50 \%$ of responders consider that owners are aware of the infection risk (from slight to very aware). This data on owner compliance in following veterinary guidance in HW shows a good degree of knowledge about and attention to animal welfare by owners regarding this severe and potentially life-threatening disease. Finally, the perception that HW infection could become endemic in naïve areas is quite high in Italy and Germany.

\section{Conclusion}

This survey gives an overview of the current experience and opinions of European veterinary practitioners on HW infection both from non-endemic and endemic countries. The general perception is that the number of cases is increasing. Although the percent of owners traveling with their dogs is relatively low, the perception is that they are quite aware of the HW risk for their dogs. More than one third of veterinary practitioners have stated that HW infection could become endemic in nonendemic areas within the next 10 years.

Table 10 How likely do you think that heartworm (Dirofilaria immitis) will become endemic in your currently non-endemic region within the next 10 years?

\begin{tabular}{|c|c|c|c|c|c|c|}
\hline \multirow[b]{3}{*}{ Country } & \multicolumn{5}{|c|}{ Perceived risk of heartworm spreading to non-endemic areas } & \multirow[b]{3}{*}{ Responders } \\
\hline & \multicolumn{5}{|c|}{ Number clinics responding (\% responding) } & \\
\hline & Not at all likely & Slightly likely & Somewhat likely & Moderately likely & Very likely & \\
\hline UK & $11(33)$ & $12(36)$ & $4(12)$ & $5(15)$ & $1(3)$ & 33 \\
\hline Germany & $18(18)$ & $30(30)$ & $28(28)$ & $23(23)$ & $2(2)$ & 101 \\
\hline Netherlands & $3(9)$ & $17(50)$ & $7(21)$ & $6(18)$ & $1(3)$ & 34 \\
\hline France & $34(40)$ & $37(43)$ & $10(12)$ & $2(2)$ & $3(3)$ & 86 \\
\hline Spain & $20(29)$ & $22(32)$ & $17(25)$ & $5(7)$ & $4(6)$ & 68 \\
\hline Italy & $3(4)$ & $12(18)$ & $25(37)$ & $16(24)$ & $11(16)$ & 67 \\
\hline Total & $89(23)$ & $130(33)$ & $91(23)$ & $57(15)$ & $22(6)$ & 389 \\
\hline
\end{tabular}




\section{Competing interest}

$J D$, is an employee of Novartis Animal Health. CG and DDB have no competing financial interests to disclose.

\section{Authors' contributions}

$J D$ prepared the questionnaires that were critically examined and approved by $C G$ and $D B$. JD sent the questionnaires to veterinary practitioners. All the authors contributed equally in examining the results and preparing the manuscript. All the authors read and approved the final version of the manuscript.

\section{Acknowledgments}

The authors acknowledge the veterinary practitioners who agreed to participate in this survey and for their information. This study was funded by Novartis Animal Health, Basel, Switzerland.

\section{Author details}

'Department of Veterinary Science and Animal Health, Università degli Studi di Milano, via Celoria 10, 20133 Milano, Italy. ${ }^{2}$ Department of Microbiology and Immunology, College of Veterinary Medicine, Cornell University, Ithaca, NY 1483, USA. ${ }^{3}$ Novartis Animal Health US, Inc., 3200 Northline Ave, Suite 300, Greensboro, NC 27408, USA.

\section{Received: 17 December 2013 Accepted: 18 April 2014}

Published: 29 April 2014

\section{References}

1. Genchi C, Solari Basano F, Marone RV, Petruschke G: Canine and Feline Heartworm in Europe with special emphasis to Italy. In Proceedings of the heartworm symposium '98, Tampa, Florida, USA, 1-3 May, 1998. Edited by Seward RLS, Batavia IL; 1998:75-82.

2. Birago F: Trattato Cinegetico, Ovvero della Caccia. Milano, Italy: V. Sfondato; 1626:77.

3. Genchi C, Rinaldi L, Cascone C, Mortasino M, Cingoli G: Is heartworm disease really spreading in Europe? Vet Parasitol 2005, 133:137-148.

4. Pantchev N, Etzold M, Daugschies A, Dyachenko V: Diagnosis of imported canine filarial infections in Germany 2008-2010. Parasitol Res 2011, 109(Suppl 1):S61-S76.

5. Sassnau R, Genchi C: Qualitative risk assessment to the endemisation of Dirofilaria repens in the state of Brandenburg (Germany) based on temperature-dependent vector competence. Parasitol Res 2013, 112:2647-2652.

6. Mortarino M, Musella V, Costa V, Genchi C, Cingoli G, Ranaldi L: GIS modeling for canine dirofilariosis risk assessment in central Italy. Geosp Health 2008, 2:253-261.

7. Otranto D, Capelli G, Genchi C: Changing distribution patterns of canine vector borne diseases in Italy: leishmaniosis vs. dirofilariosis. Parasit Vectors 2009, 2((Suppl 1):S2. http://www.parasitesandvectors.com/content/2/S1/S2.

8. Giangaspero A, Marangi M, Latrofa MS, Martinelli D, Traversa D, Otranto D, Genchi C: Evidences of increasing risk of dirofilarioses in southern Italy. Parasitol Res 2013, 112:1361-1375.

9. Otranto D, Dantas-Torres F, Brianti E, Traversa D, Petrić, Genchi C, Capelli G: Vector-borne helminths of dogs and humans in Europe. Parasit Vectors 2013, 6:6-15.

10. Mircean V, Dumitrache MO, Györke A, Pantchev N, Jodies R, Mihalca AD, Cozma V: Seroprevalence and geographic distribution of Dirofilaria immitis and tick-borne infections (Anaplasma phagocytophilum, Borrelia burgdorferi sensu lato, and Ehrlichia canis) in dogs from Romania. Vector Borne Zoonotic Dis 2012, 12:595-604.

11. Świątalska A, Demiaszkiewicz AW: First autochthonous case of Dirofilaria immitis invasion in dog in Poland. Žycie Weterynaryjne 2012, 87:685-686 [in Polish]

12. Kronefeld M, Kampen H, Sassnau R, Werner D: Molecular evidence for the occurrence of Dirofilaria immitis, Dirofilaria repens and Setaria tundra in mosquitoes from Germany. Parasit Vectors 2014, 7:30. http://www. parasitesandvectors.com/content/7/1/30.

13. McCall JW, Genchi C, Kramer LH, Guerrero J, Venco L: Heartworm disease in animals and humans. Adv Parasitol 2008, 66:193-285.

14. ESCCAP GL5. 2012. http://www.esccap.org/uploads/docs/ih38c2d6_ESCCAP_ Guidelines_GL5_010ct2012.pdf.
15. Thomas RE: A case of canine heartworm disease (Dirofilaria immitis) in the UK. Vet Rec 1985, 117:14-15.

16. Meyer HP, Wolvekamp P, van Maanen C, Stokof AA: Seven cases of heartworm disease (dirofilariosis) in dogs in The Netherlands. Vet Q 1994, 16:169-174

17. Sassnau R, Kohn M, Demeler J, Kohn B, Müller E, Krücken J, von SamsonHimmelstjerna G: Is Dirofilaria repens Endemic in the Havelland District in Brandenburg, Germany? Vector Borne Zoonotic Dis 2013, Aug 6. [Epub ahead of print]

18. Genchi C, Mortarino M, Rinaldi L, Cringoli G, Traldi G, Genchi M: Changing climate and changing vector-borne disease distribution: the example of Dirofilaria in Europe. Vet Parasitol 2011, 176:295-299.

doi:10.1186/1756-3305-7-206

Cite this article as: Genchi et al:: Canine heartworm disease (Dirofilaria immitis) in Western Europe: survey of veterinary awareness and perceptions. Parasites \& Vectors 2014 7:206.

\section{Submit your next manuscript to BioMed Central and take full advantage of:}

- Convenient online submission

- Thorough peer review

- No space constraints or color figure charges

- Immediate publication on acceptance

- Inclusion in PubMed, CAS, Scopus and Google Scholar

- Research which is freely available for redistribution

Submit your manuscript at www.biomedcentral.com/submit
Ciomed Central 